\title{
Design of Interactive Television Programs
}

\author{
Leena Eronen \\ Telecommunications Software and Multimedia Laboratory \\ Helsinki University of Technology \\ P.O.Box 5400, FI-02015 HUT, Finland \\ +35894515130 \\ leronen@niksula.hut.fi
}

\begin{abstract}
This paper presents results from a set of design sessions held in a broadcasting company. The aim of research was to find a user centered design method which includes the future users into the product development in the early stages of new product design. In this case, the products were interactive television programs and applications for digital television. The study also aims at creating a design method with the user study participants as equal research partners with the designers.

The study started with a user study in study participants' home environment. The user study results, a set of user profiles, was taken to a broadcasting company. A series of five design sessions with participants from the broadcasting company followed. New concepts of interactive television programs were designed during the design sessions. The study resulted in new concepts of interactive television programs and services for digital television that were created by both TV viewers and designers.
\end{abstract}

\section{Keywords}

Digital television, concept design, innovation

\section{INTRODUCTION}

Interactive television programs and applications have been a subject of research in a number of studies. There are results from prototyping personalized TV news [12] and usability testing, namely Electronic Program Guide prototypes [5], interactive multimedia services [9] and the access to PC functionality and applications [3]. In some studies, the focus of research has been on the on-screen displays and remote controls [11]. Besides that, there is work related to the television use in general, for example, a diary study including 500 TV viewers [7], an ethnographic study of set-top-box use [13] and a study resulting in a set of user groups for digital television [4]. It is concluded that we need more research which includes TV viewers in the discipline of designing interactive television programs and applications. We also need research on how to best receive feedback from them.

\section{Aim of the Study}

The main research question is, how to gather data on TV viewers and their home environment, and what influence this data has on the design process of interactive television programs.

\section{CONCEPT DESIGN}

Professional design practice is a field that serves and shapes our daily lives. Design of consumer products and the everyday material world deserves attention not only as a professional practice but as a subject of social and cultural investigation. This has led to user centered design practices and the identification of the user as a collaborator with the designer. The next subsections deal with issues concerning user research and concept design.

\section{Concept Design of New Products}

Concept design of innovative new products is challenging. It is difficult to determine or predict how people will act with new ideas, technologies or innovations. The limit of user research has to do with the capability of users to say to researchers what they really want or to predict how they will really behave with a new product or service. Instead of expecting the users to express a need for a particular product, researchers can try to identify those areas in users' lives related to a product category where users express conflict or ambivalence [6]. Such ambivalence covers not only what users need from that product category, but also the meaning they receive from the category in the context of the rest of their lives. These expressions that perhaps were ignored in the past can present opportunities for producing market-creating innovations in the future.

Other new methods for concept design take advantage of new techniques such as role playing and theater techniques. These new techniques are good at highlighting the function of or interaction with a new technology. When new or unusual technologies are presented to the future users of a product in a live theater performance, often the audience accepts and understands their function. For example bodystorming, dramatic improvisation and role playing are used [2]. Role playing can take place in both staged and real situations, and the users can take part in the role playing games as players [10]. The resulting vivid experiences create lasting memories which influence and guide the designers' choices and actions throughout the design process.

\section{Television and the Home Environment}

The home is at different times a place of escape, a place of work, a place of privacy and a place of public exhibition of the tastes and values of the householders living there. Much of what people do inside and outside the home is socially 
driven and based on communication. Personal, inter-family communication has a purpose to express intention and emotion. Studies have been made in the area, for example, a study on envisioning new media for family communication [14].

Telecommunications and entertainment industries treat the home as the next site for technological development. There are already new information technologies for the home which link the computer with communication and entertainment technologies. Examples of such new applications for the home are domestic banking, home shopping and video on demand. Digital television will inevitably help the convergence of technologies.

\section{METHODS}

Ethnographic user research is usually based on field trips [1]. The study presented here consists of a user study and a set of design sessions. It is a continuation on a study resulting in a set of user groups for digital television [4]. The user study took place in study participants' home environment. It must be stated that the research method was not 'ethnographic research' in a sense that the ten user study participants, instead of researchers, collected the data. The research approach enabled the users themselves to gather the results, explain them and give their interpretations as why events happened.

\section{User Study}

Five women and five men in the age range of 16-78 years received an envelope with questionnaires, separate questions, two diaries and a disposable camera. The approach has been adapted from a research called 'Cultural probes' [8]. The study participants also designed innovations of future interactive applications for themselves. A subsequent one-hour interview with the researcher revealed more of the study participants' needs for specific types of information and their thoughts of the television in the future.

The user study resulted in a large amount of ethnographic data: questionnaires, diaries, photographs, users' innovations and notes from the interviews. The study participants also made scenarios about what their television will look like in year 2006, five years ahead of the present moment.

The user study results were collected in ten separate user profiles, each 8-18 pages in length. One of the user profiles is presented here next. For the purposes of this paper, it has been shortened to fit one page. All names have been changed to protect privacy. Figure 1 illustrates Martin in his living room. This is one of the photographs the study participants were asked to take that presents their daily life and the objects and incidents at home.

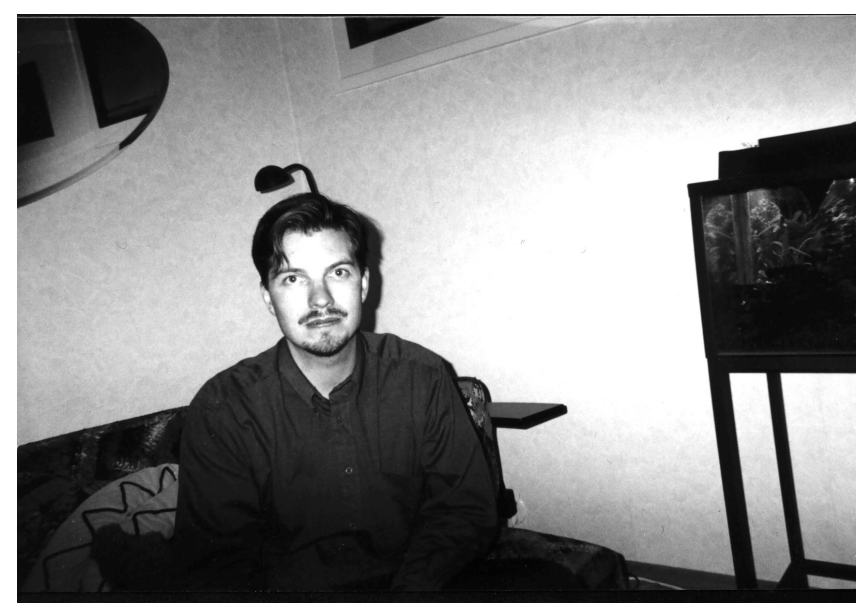

Figure 1. Martin in his living room.

User profile: Martin, 27 years, Product manager

Family: Madeleine 26 years, Kristina 5 years

Pets: An aquarium.

Devices at home: TV, VCR, CD player, home theater equipment, two PCs, Internet connection, read /write CD drive, DVD player, printer, scanner.

Martin prefers to watch: Animation, Art, Documentaries, Economics, Foreign movies, Music (Rock, pop, dance), Nature, Quiz.

"In your opinion, what is best about television?" "Watching entertainment program where you don't have to think or do anything."

"In your opinion, what is worst about television?" "You can't think or do anything while watching the television. It's too passive if you wanted to have more active entertainment."

"Which video tapes are most important to you?" "Classic (foreign) movies are important. Also serials like Men in Black and Frasier are important to put on video if you don't have time to watch them immediately."

"What do you prefer to do on your leisure time?" "We often go swimming with the child, and I go to play badminton. We go to movies."

Martin was asked to think what his television will look like in year 2006, five years ahead of the present moment. Martin said about his television in the future: "The television would recommend me the same type of TV shows I've watched before and there is a quick on-demand online quiz that doesn't disturb watching the TV shows. We play board games like Trivial Pursuit from the set-top-box memory with the family. I can send text messages to friends with a snapshot I've taken with a digital camera and there is a family photo album on TV. I can Home Shop with a catalog on the TV screen." 


\section{Favourite Future Applications}

A list of 22 possible future applications for digital television was created and the study participants were asked to rate the services. The question was: "They want to make the digital television as a personal tool for gathering entertainment and information. Which of the next applications and services are of interest to you?"

\section{+3 Interests a lot}

+3 Bookshop on the Internet

+3 Bus and train timetables

+3 Information of the ongoing TV show

+3 Internet chat

+3 Electronic Program Guide for 7 days

+3 Email on TV

+3 Grocery shop on the Internet

+3 Home shop

+3 Web on TV

+3 Job hunting

+3 Local events /City guide

+3 Music video on demand

+3 Domestic banking

+3 Online movie tickets

+3 Online quiz while watching the TV show

+3 TV program recording into set-top-box memory

+3 Web pages for TV channels

+3 TV games

+3 Video on demand

+3 Yellow Pages

\section{Interests in some degree}

-2 One-touch dial for preset Teletext pages

-2 Teletext

\section{-3 Interests a little}

The results show that Martin has a strong interest in TVand Web-based services that present the new technology. $\mathrm{He}$ is not interested in Teletext which is considered old technology. The problem with such questionnaires is that it is hard to predict if the person's curious first trials of new technology will make him a frequent user of the new services.

\section{Concept Design Sessions}

We wanted to create new concepts of interactive television programs for digital television with the aid of user profiles. A set of user profiles was taken to a public service broadcasting company YLE (Finnish Broadcasting Company). The number of YLE program hours in the Finnish-language television network was 11,114 hours during year 2001 and their share of total TV viewing was $43 \%$.

There was a series of five design sessions which included two participants from YLE and a researcher. Altogether ten participants from YLE took part in the sessions which were recorded for later inspection. Each session took 60-90 minutes. The session participants explored the user profile, the photographs and a shortened transcription of the interview with the user. The aim of each session was to concentrate specifically on one $\mathrm{TV}$ viewer at a time instead of groups of people familiar from the audience research.

First the session participants read through the user profile. A conversation followed focusing on user's current TV use, his favourite television programs, leisure time activities and other preferences. During the conversation, new concepts of interactive television programs and services were written down for this particular TV viewer. At the end of the session, the two session participants were asked to write a short description which in their opinion described the most important characteristics of the user. The user's innovations were then presented to session participants as a feedback. The designers could now compare the user's innovations with the new concepts they had created themselves. This was a way to provide an instant feedback to designers.

\section{RESULTS}

The outputs of the design sessions are presented here next. Both the short description of each TV viewer and the new concepts made for this TV viewer are presented. The basic idea of a new television program is described in the form of a conversation between the session participants. A conversation is used to describe the reasons why session participants thought the new program concept would suit this particular TV viewer. For the purposes of this paper, the fifth design session was left out and the conversations were shortened into a few lines.

For new concepts of interactive television programs and services, it is anticipated that the interactivity can occur in different ways. There can be a user interaction with the remote control and the set-top-box, a text message sent from a mobile phone, a phone call or a postcard sent to the TV show.

\section{First Design Session}

First design session included the head of the development division of television programs and a concept designer of television programs. Their work is to analyze TV viewer polls, make television programs more interesting to watch, innovate new television program formats and make better usability in the digital television era. The user profile under discussion presented a 34-year-old children's nurse whom the session participants described as follows:

- She is a heavy consumer of television programs, especially the studio entertainment. 
- She is a 'Fundamental Finn', home-centered with a basic education.

- She has an interest in domestic reality-based entertainment programs, cases on criminal investigation and the Wheel of Fortune television programs.

- She is a passionate Formula 1 spectator.

Two of the new concepts or television program formats designed for her are presented here:

Chat for Formula 1 fanatics: "This family can't go to their summer house when there is Formula 1 racing on TV. I think she could chat with other TV viewers about the TV show she is watching at. She was quite competent in the TV programs she watched at regularly." "It is not necessarily a free chat channel, but a chat with a host with chat participants who are Formula 1 experts just like her. The chat would be in Finnish for her convenience and she could watch the race at the same time in the background."

Criminal investigation program: "She has six favourite programs on criminal investigation. What if she could see a criminal investigation program based on historical material, a type of documentary? The program could include dramatized scenes from the past and then show a link to the present day, just like the Police TV show where there are shots of the camera crew following a patrol in action." "She could solve some cases herself, too. First they show the scene to TV viewers and give some clue to the case, and then they ask the TV viewers to send their solutions to the show. This takes place in a text message or there is an applet in the set-top-box memory. The "right answer' to the mystery would be exposed next week."

\section{Second Design Session}

Second design session included two television editors who make television programs on subjects such as culture, literature, adult education and the information society. Figure 2 illustrates the session participants of the second design session excluding the researcher who took the photographs. The user profile in the second session presented a 46-year-old chief coastguard whom the session participants described as follows:

- Home and family are important to him.

- He is interested in sports and entertainment and he wants to participate in the television program only a little.

- He is comfort oriented and bustling.

- He is moderately interested in the new technology.

One of the new concepts or television program formats designed for him is presented here:

Our family life: "They live in a one-family house. He said he has built it himself. Could you have a program on what it is like to live in a one-family house as a type of living? You take every aspect there is: The maintenance of the house, the kitchen work and cooking, gardening, heating the sauna, etc."

Eronen, L. (2002) Design of Interactive Television Programs. In Proceedings of the 3rd Annual ACM SIGCHI-NZ Symposium on Computer-Human Interaction CHINZ 2002 (July 11-12, Hamilton, New Zealand), ACM SIGCHI-NZ, 73-78.

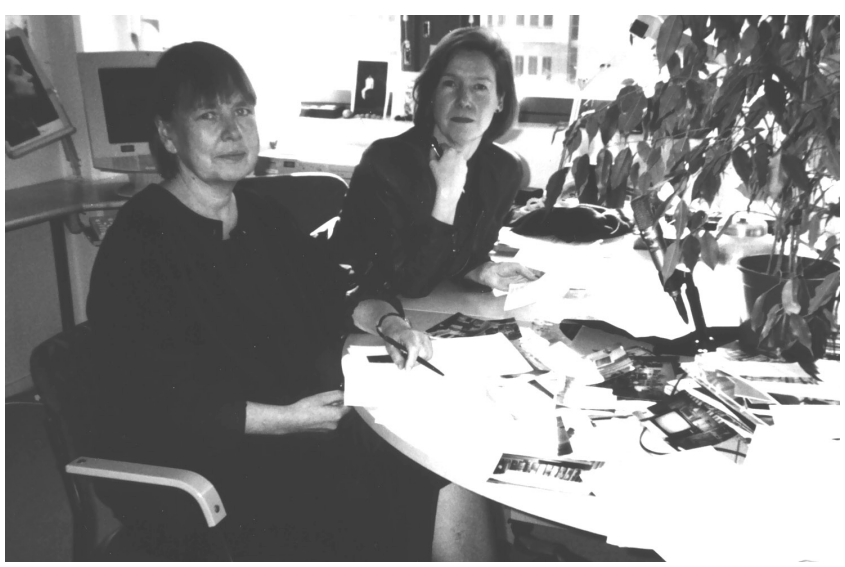

Figure 2. Participants of the second design session.

"But it is a Finnish dream, to live in a one-family house with a small garden, isn't it? Doesn't everyone day-dream about that?" "Yes, you have privacy. If the name of the program is 'Our family life', you could have current affairs in 'Women's corner' and 'Men's corner', and human relations skills and parenting."

"You can make this a series for one hundred years! If the house is on the lakeside, you can show how to build a pier, or how to fix it, or how to make a pool. You can also have examples of 'How to get along with your neighbour'. There you see dramatized scenes of conflicts and situations where $T V$ viewers find it too difficult to participate and come to the TV show in person." "As it is an interactive TV program, we have a 24-hour phone line where TV viewers make a call and dictate their own stories. The next week you see your story dramatized on TV and other TV viewers can call the show or send an email to the studio and give their suggestions as how to best solve the situation." "That's a good idea. In general, people love to talk about their opinion when somebody asks them to do so."

Third Design Session

Third design session included two television producers who make television programs on subjects such as Internet, new technology, science and adult education. The user profile under discussion presented a 16-year-old high school student whom the session participants described as follows:

- Typology: He is an entertainment oriented teenager.

- For him, the most important thing is that the life is running smoothly.

- Why does he watch TV? For entertainment, relaxation, to clear his mind of other thoughts.

One of the new concepts or television program formats designed for him is presented here:

Science program for teenagers: "The question is, how to reach this teenager? There are no documentaries on his list of favourite TV programs. The only incident when he is 
mentioning the documentaries is when he says they sometimes watch them at school during a history lesson. I think schools could market science programs in their media education." "I see the Internet as a means to reach him. Of course YLE channels are a marketing channel and maybe newspapers too. The newspaper could give you the headlines as what's on the show tonight. Furthermore, teenagers are quite critical in their taste for TV programs. If you interview, for example, 13-year-olds in the show, all 15-year-olds will say 'No, it is a children's program, it's not for me!'”

"The style of the program must be raffish, with proper graphics and shaking the camera.. People of different ages and backgrounds could do the program. Teenagers are interested in young celebrities like singers and musicians. They also know small secrets and scandals about them." "The show could deal with issues that are of interest to teenagers, for example, how Darude makes music with computers, or how you edit a home video. To make it an interactive TV program, TV viewers could send text messages to the show or the Web pages. You could ask for teenagers' opinion on the Question of the week, etc."

\section{Fourth Design Session}

Fourth design session included two researchers from the Audience Research unit. They do research on TV viewers, conduct focus group sessions and do other qualitative research. The user profile under discussion presented a 78year-old retired woman whom the session participants described as follows:

- She prefers television programs of good mood and good news, with pleasant people on the show.

- Television programs must move on at a quiet pace, providing small amounts of information at a time.

- Remembering of memories from her past is important to her.

- Don't force the new features of interactive television on these people, rather tell them what to do.

One of the new concepts or television program formats designed for her is presented here:

Memories of recent history: "People of her age are extremely worried about their memory, and which are the things they can still remember, properly and accurately." "Our program could give her some material for recall. The TV show could address issues of recent history from politics to pop music, from fashion to daily life. We could play with the idea of 'How much do you still remember of..' For example, the show could present black-and-white video from the archives, something that was quite popular at the time and therefore easy to recall. The program would proceed one year at a time, starting from year 1950."

"We could ask the TV viewers to write or call us and tell, for example, 'Which event do you remember from that year particularly?', or 'What was important to you at that time?'. We make an interview with someone who sent us an interesting recollection, by mail or phone. This is also a TV program that tells the young generation how people lived before. It is a way to transfer the cultural heritage, to maintain the memory of a generation." "It is important to $T V$ viewers of her age to be able to sit back and relax. We cannot force the features of interactive television on these people, we rather tell them what to do if they have an interest to participate in the TV show."

\section{CONCLUSION}

This paper presented results from a user centered design method which included the future users into the product development of interactive television programs and applications. First a user study was made in study participants' home environment. The study results, a set of user profiles, was taken to a broadcasting company. A series of five design sessions with ten participants from the broadcasting company followed. The aim of each session was to concentrate specifically on one TV viewer at a time instead of groups of people familiar from the audience research. The design sessions resulted in new concepts of interactive television programs and services for digital television.

Design implications of this user centered design method deal with gathering the user data and transforming the data into new product concepts. Future research has two goals: First, we need to find a qualitative method to compare the user study results against the new concepts made by the designers. We want to find out how users' and designers' concepts of future differ from each other and which concepts are likely to suit a large audience. We also want to know in which areas were users more competent to bring out new ideas than the designers, and on the contrary, is there an area were designers have more to say than users? Second, we want to compose scenarios of some selected concepts to get feedback from a group of TV viewers.

\section{DISCUSSION}

It was found during the design sessions that sometimes the session participants found it difficult to design new concepts for a given TV viewer. They said the TV viewer was older or younger than the group of people they considered as 'their audience'. In the future, the session participants could choose 'their TV viewer' themselves from the ten user profiles beforehand. This could increase the session participants' curiosity, motivation and commitment to the design session.

It was also found that the female session participants could verbalize their ideas easier than their male counterparts. Maybe males felt more confident with issues considered as 'known facts about the TV viewer' than 'my opinions about the TV viewer' or 'my opinions about which concepts could suit the TV viewer'. As the preceding sentence is pure guesswork, we could test the issue in the future with new design methods and see if they help all session participants to bring out their ideas. Less-verbal or competitive design Eronen, L. (2002) Design of Interactive Television Programs. In Proceedings of the 3rd Annual ACM SIGCHI-NZ Symposium on Computer-Human Interaction CHINZ 2002 (July 11-12, Hamilton, New Zealand), ACM SIGCHI-NZ, 73-78. 
methods include role playing and theater techniques, writing in a team and information searching tasks. Maybe a little competion of 'best new designs' could help the session participants to forget that they are shy to bring out their opinions.

Sometimes it was difficult to create new interactive concepts as the public service broadcasting company YLE is not allowed to compete with the commercial TV channels. For example, all the Wheel of Fortune -type of program concepts had to be left out as the TV viewer has the potential for winning money in the program.

The session participants said during the sessions that "The feedback from the audience is always a surprise" and "You can't say for sure beforehand if the TV viewer will be pleased with this new concept or not". To get feedback from the audience in the early stages of new television programs, it could be a good idea to test the new concepts in a live theater performance where a live audience can give an instant feedback to both the actors and the script writers. Also different story endings and characters can be tried out, or different types of actors for the same role. As it is expensive to make a pilot of a new program concept, an instant feedback from a live audience can help to reduce costs before making the pilot.

\section{ACKNOWLEDGMENTS}

Sincere thanks to all session participants from YLE who contributed to the success of the design sessions! The author also wants to express her appreciation for the user study participants who provided their time and help for the research on their leisure time. Without these twenty people, the study wouldn't have been accomplished. The author has received a scholarship from YLE 75 Years Fund.

\section{REFERENCES}

1. Blomberg, J., Giacomi, J., Mosher, A. and SwentonWall, P. Ethnographic Field Methods and Their Relation to Design, in Schuler, D. and Namioka, A. (eds.) Participatory Design: Principles and Practices. Lawrence Erlbaum Associates, Hillsdale, NJ, USA, 1993.

2. Buchenau, M. and Suri, J. F. Experience Prototyping, in Conference proceedings on Designing interactive systems DIS '00: processes, practices, methods, and techniques (August 17-19, 2000, Brooklyn, NY, USA), ACM Press, 424-433.

3. Bødker, S., Nielsen, C. and Petersen, M. G. Creativity, Cooperation and Interactive Design, in Conference proceedings on Designing interactive systems DIS '00: processes, practices, methods, and techniques (August 17-19, 2000, Brooklyn, NY, USA), ACM Press, 252261.

4. Eronen, L. Combining Quantitative and Qualitative Data in User Research on Digital Television, in Proceedings of the 1st Panhellenic Conference with International Participation on Human-Computer Interaction PC HCI 2001 (December 7-9, 2001, Patras, Greece), Typorama Publications, 51-56.

5. Eronen, L. and Vuorimaa, P. User Interfaces for Digital Television: a Navigator Case Study, in Proceedings of the Working Conference on Advanced Visual Interfaces AVI 2000 (May 23-26, 2000, Palermo, Italy), ACM Press, 276-279.

6. Flores Letelier, M. F., Spinosa, C. and Calder, B. J. Taking an Expanded View of Customers' Needs: Qualitative Research for Aiding Innovation. Marketing Research 12, 4 (Winter 2000), 4-11.

7. Gauntlett, D. and Hill, A. TV living: Television, culture and everyday life. Routledge, London, United Kingdom, 1999.

8. Gaver, B., Dunne, T. and Pacenti, E. Design: Cultural Probes. Interactions 6, 1 (January 1999), 21-29.

9. Hvannberg, E. T. and Larusdottir, M. K. Usability Testing of Interactive Multimedia Services, in Proceedings of the NordiCHI2OOO conference, (October 23-25, 2000, Stockholm, Sweden), NordiCHI and STIMDI, 8 pages.

10. Iacucci G., Kuutti K. and Ranta, M. On the Move with a Magic Thing: Role Playing in Concept Design of Mobile Services and Devices, in Conference proceedings on Designing interactive systems DIS '00: processes, practices, methods, and techniques (August 17-19, 2000, Brooklyn, NY, USA), ACM Press, 193202.

11.Logan, R. J. Behavioral and Emotional Usability: Thomson Consumer Electronics, in Wiklund, M. E. (ed.) Usability in Practice: How Companies Develop User-Friendly Products. AP Professional, Boston, MA, USA, 1994.

12. Marrin, C., Myers, R., Kent, J. and Broadwell, P. Steerable Media: Interactive Television via Video Synthesis, in Conference proceedings on 3D technologies for the World Wide Web WEB3D '2001 (February 2001, Paderbon, Germany), ACM Press, 715.

13. O'Brien, J., Rodden, T., Rouncefield, M. and Hughes, J. At Home with the Technology: An Ethnographic Study of a Set-Top-Box Trial. ACM Transactions on Computer-Human Interaction 6, 3 (September 1999), 282-308.

14. Tollmar, K., Junestrand, S. and Torgny, O. Virtually Living Together, in Conference proceedings on Designing interactive systems DIS '00: processes, practices, methods, and techniques, (August 17-19, 2000, Brooklyn, NY, USA), ACM Press, 83-91. 